\title{
Towards Enterprise Technical Architecture for the Implementation of the South African NHI
}

\author{
Farirai Chitsa, Tiko Iyamu*
}

Cape Peninsula University of Technology, Department of Information Technology, District Six, South Africa

\begin{tabular}{l} 
A R T I C L E I N F O \\
\hline Article history: \\
Received: 12 February, 2020 \\
Accepted: 07 March, 2020 \\
Online: 20 April, 2020 \\
\hline
\end{tabular}

Keywords:

Enterprise architecture

Technical architecture

Universal health coverage

National health insurance

IT project implementation

\begin{abstract}
A B S T R A C T
This paper provides an insight about the significance of the enterprise technical architecture (ETA) in enabling and supporting the implementation of the South African National Health Insurance (NHI). Design: Existing documentations from both academic and government domains were gathered, and analyzed using the hermeneutics technique, from the perspective of interpretivist approach. Based on the analysis, the paper reveals the cruciality of the ETA in the implementation of the Universal health coverage (NHC) in the South African environment. The paper is intended to be of use for the core stakeholders of the NHI, which include governments' administrations, IT specialists, health practitioners, as well as academics.
\end{abstract}

\section{Introduction}

The national health insurance (NHI) is a universal health program, new in South Africa. At the time of this study in 2019, the program was being piloted. Owing to the newness of the program, stakeholders constituting a complex mixed bag, sensitivity nature of patients' datasets, and the complexity of information systems and technologies (IS/IT) solutions, the implementation will be inevitably challenging, which can potentially derail the entire program. From IS/IT perspectives, the challenges can be associated with factors such as lack of appropriate design and governance, which manifest into stagnation, disintegration of technology infrastructures, manipulation of information, and processes. Thus, an enterprise technical architecture (ETA) is required in addressing the fundamental challenges in enabling and supporting the implementation of the NHI.

The Universal Health Coverage (UHC) is a program that is aimed at increasing coverage and access to healthcare [1]. Both developed and developing countries such as Canada, Brazil, Taiwan, United states of America (USA), United Kingdom (UK) has adopted the program under different names, but with similar goals and objectives, in recent years [1]. It is National Health System (NHS) in the UK, Universal Health-care System (UHS) in Canada, and Obamacare in the USA [2]. The quality of life, as well as the healthcare of the Taiwanese, is said to have improved, leading to a better life expectancy as a result of the UHC in the

"Corresponding Author: Tiko Iyamu, Email: connectvilla@yahoo.com

www.astesj.com

https://dx.doi.org/10.25046/aj050290 country [3]. The National Health Insurance (NHI) is the South African version of the UHC [4]. The department of health (DoH) is the custodian of the program.

The aim of the NHI is to ensure that all South Africans have access to good quality health care, disregarding their socioeconomic status [4]. The anticipated benefits of NHI include elimination of out of pocket payments, removal of discrimination in terms of salary bracket, provision of universal health care to all with preference based on the illness and not affordability among others [5]. Cheng explains how the Taiwanese are benefiting from the country's NHI system, as they enjoy ease of access to health services including specialists, choice of health care provider and short waiting times [6]. The NHI is more about ensuring extended coverage and increased access to health services regardless of socio-economic status [7]. It is therefore intended to address challenges within the South African health sector, which has become severe due to the lack of equitable access to healthcare [4].

The UHC has yielded huge benefits to many countries such as the UK and Taiwanese [3]. The benefits hasn't been without challenges in some countries, from information technology (IT) perspective. In the USA, the Obamacare was hacked the same day it went on live [2]. The Canadian universal health-care system (UHC) is challenged with ease of access from different locations [8]. Cases and challenges from other countries are enough for the promoters and implementers of the South African NHI to be more prepared. Thus, there should be emphasis on the IS/IT solutions that enable and support the program. One of the approaches is to 


\section{F. Chitsa et al. / Advances in Science, Technology and Engineering Systems Journal Vol. 5, No. 2, 724-729 (2020)}

deploy the enterprise technical architecture (ETA) for the implementation of the NHI.

The assessment of the ongoing pilot of the NHI, it was reported that at the end of 2018, 20-million people were registered, but poor connectivity, hardware problems and lack of IT staff hinder some clinics from accessing the internet [9]. It has been proven that poorly designed systems affect the implementation of IT systems in healthcare [10]. Many of the IS/IT solutions' challenges manifest from lack of governance [11]. The ETA bridge the gap between enabler and the enabled, pragmatics assessment and of technology solutions in addressing needs, semiotics of IS/IT solutions' deployment [12]. The technical architecture stabilizes the deployment and use of IS/IT solutions in an environment [13]. Without architectural guidance, IS/IT solutions encounter challenges, and ultimately fail to enable and support goals and objectives towards fulfilment. It is based on this concern and gap that this study examines, and presents a discussion which can lead to the development and deployment of enterprise technical architecture (ETA) for the implementation of the South African NHI.

In order to give clearance, this paper is structured into six main sections, starting with the introduction, which is followed by reveal of related studies and the methodological approach that was applied in the study. Fourth section presents a discussion towards which an ETA can be built for the implementation of the NHI. Finally, a conclusion is drawn.

\section{Related studies}

The use of IS/IT in the health sector improves the efficiency and effectiveness of the healthcare system [14], hence there is a need to invest more in the enabling solutions, to reduce some of the challenges [15]. This includes electronic storing as well as remote monitoring and accessing of patients' records [16].

The IS/IT solutions are increasingly used to play significant role in the delivering of healthcare services [17]. It was on this basis of signification that Phichitchaisopa and Naenna emphasized on the selection of ICT artefacts for enabling healthcare processes and activities [18]. This is to mitigate against the numerous challenges that constantly confront the health processes and activities, such as legislators, policy, governance, and systems design, integration and implementation [10]. The challenges can be worst in the South African environment in that it is a 'green field' for the UHC. Currently, public health facilities in South Africa are struggling in terms of the quality of service that they provide to the community [19]. There are poor ICT infrastructures in most parts of South Africa, which utimately have impact on the adoption of health systems in the country [20]. This can be attributed to the state of IS/IT solutions that enable its functions. This makes case for more financial investment on IT solutions in enabling and supporting health care systems so as to improve service delivery through reponse time, and ease of access to patients' records [18]. Passchier therefore suggests the need for IT investment for the implementation of the NHI in the country [21].

The amount of investment on IS/IT does not necessarily determine the success or quality of the solutions. Successful implementation of IS/IT solutions is influenced by various factors, which the NHI is currently lacking. Child argue that successful implementation of IT systems require interaction between the users, technologies, and organisational processes [19]. According to 'cheng, the introduction of new technologies as well as velocity and variety of diseases can influence or strain IT systems including the budget [6]. In addition, connectivity, complexity of systems, reliability of software and hardware, human resources among others can also influence the implementation of ICT enabled systems such as the NHI [22]. These are factors and challenges that the South African NHI needs to focus on from the IS/IT perspective. Unfortunately, this aspect has been silent in the policy and strategic documents that gazetted between 2013 and to-date including some assessment reports [23,9].

There has been so much emphases towards funding and other non-technical issues, and less attention on the enabler. In order to achieve the goals of UHC, the NHI system needs to be well financed [24]. This can be serious mistake. Like every other system, the NHI requires IS/IT solutions such as to software, hardware, network for its enablement [25]. However, the solutions include integration, security and governance, to ensure efficiency in operationalising and fulfilling the goals and objectives of the program.

As much as the use of ICT in health care systems has been increasing and of beneficial, it however, comes with challenges mainly regarding the concerns of security and privacy of sensitive data [26]. The challenges of implementation of IS/IT solution for healthcare service delivery can be attributed to many factors, such as cultural, economic, geographical and political settings of the environment $[27,1]$. The Brazilian's unified health system is still facing challenges due to geographical factors which affect the equitable distribution of health care services in terms of resources and technologies [28]. Lack of standards can also affect the successful implementation of ICT solutions [29]. The Norwegian health sector experienced uncertainty of ICT infrastructure and solutions that was acquired without an architecture which led them to implementing one [30].

The NHI implementation requires combination, co-existence, and integration of various IS/IT solutions, such as software, hardware platforms, network protocols, and databases towards achieving its goals [8]. Interoperability is of paramount importance as medical data and information would be shared among different entities [31]. This is not without architectural deployment. Also, despite the interest and wareness to automate health information systems for NHI, which include transitioning from manual to electronic processes and interoperability of IS/IT solutions, the deployment of ETA is still silent. One of the definitions of the domain: ETA is a logically consistent set of principles, standards and models that are derived from vision, strategy in order to guide the engineering of IS/IT solutions within context [12].

\section{Methodological approach}

This is an exploratory case study of the implementation of the South African NHI. Yazan defines this type of study as an inquiry of a phenomena, to gain a better understanding of a bigger class of units [32]. The conceptual and explanatory nature of the study makes the case approach suitable for the study [33].

The data was gathered from two sources, documentation relating to NHI by using the document analysis technique; and 


\section{F. Chitsa et al. / Advances in Science, Technology and Engineering Systems Journal Vol. 5, No. 2, 724-729 (2020)}

transcript of focus group. These sources were considered most suitable for the following reasons: (1) the documents were passed into bill by the legislative arm of the government, making them authentic and legal, and (2) the focus group had a balanced representation from the public, government, and health practitioners.

The document analysis is often used to extract rich content. Sherif describes the technique as a detailed examination of data that can be collected from sources such as peer-reviewed articles, official reports, and policies documents with a specific goal of understanding the documents within context [34]. The technique helps to extract specific insights and key information for the purposes of the phenomenon being studied [35]. As shown in Table 1, different documents were collected for this study.

Table 1: Documentations

\begin{tabular}{|c|c|c|}
\hline Title & Description & Source \\
\hline $\begin{array}{lr}\text { National Health } \\
\text { Insurance } \\
\text { South for } \\
\text { Towards universal } \\
\text { health coverage }\end{array}$ & $\begin{array}{l}\text { 1-80 pages: } \\
\text { Government } \\
\text { Gazette, } 30 \text { June } \\
\text { 2017. No. } 40955 .\end{array}$ & $\begin{array}{l}\text { Department of } \\
\text { health, Republic of } \\
\text { South Africa. } \\
\text { Www.gpwonline.co. } \\
\text { za }\end{array}$ \\
\hline $\begin{array}{lr}\text { National } & \text { Health } \\
\text { Insurance } & \text { for } \\
\text { South } & \text { Africa } \\
\text { Towards universal } \\
\text { health coverage }\end{array}$ & $\begin{array}{l}\text { 1-98 pages: } \\
\text { Government } \\
\text { Gazette, } 11 \\
\text { December } 2015 . \\
\text { Ref No. } 39506 .\end{array}$ & $\begin{array}{l}\text { Department of } \\
\text { health, Republic of } \\
\text { South Africa. } \\
\text { Www.gpwonline.co. } \\
\text { za }\end{array}$ \\
\hline $\begin{array}{l}\text { Status of NHI } \\
\text { Pilot districts } \\
\text { 12-month } \\
\text { progress report }\end{array}$ & $\begin{array}{l}\text { 1-44 pages: } \\
\text { Assessment of } \\
\text { the NHI pilots. } \\
25 \text { May 2015. }\end{array}$ & $\begin{array}{l}\text { Department } \\
\text { health, Republic of } \\
\text { South Africa }\end{array}$ \\
\hline $\begin{array}{l}\text { National Health } \\
\text { Insurance in South } \\
\text { Africa }\end{array}$ & $\begin{array}{l}\text { 1-59 pages: } \\
\text { Policy document } \\
\text { for the NHI }\end{array}$ & $\begin{array}{l}\text { Department of } \\
\text { health, Republic of } \\
\text { South Africa. } \\
\text { Www.gpwonline.co. } \\
\text { za }\end{array}$ \\
\hline $\begin{array}{lr}\text { National } & \text { Health } \\
\text { Insurance: } & \text { pilot } \\
\text { projects reveal } & \text { rever problems }\end{array}$ & $\begin{array}{l}\text { Assessment of } \\
\text { pilot projects in } \\
11 \text { health districts } \\
\text { countrywide } \\
\text { between } 2012 \\
\text { and } 2017\end{array}$ & $\begin{array}{l}\text { Katherine Child, } 28 \\
\text { July } 2019 .\end{array}$ \\
\hline
\end{tabular}

The focus group method was employed it helps participants to recall their past experiences through interaction with other stakeholders [36]. A radio program was used as a source in the collection of data from the focus. The program was hosted by the South African Frequency Modulation (SAFM) on the http://www.safm.co.za/sabc/home/safm/multimedia. The SAFM is a national radio station. The station, arguably has the highest number of audience, listeners in the country. The participants included the host-presenter, two guests (each represented the government and health practitioners), and members of the community. The interview was conducted in the form of discussion. It was facilitated by the host-presenter between the guests and the callers (community members). It was an hour program. The transcript of the podcast forms part of the data that was used in this study.

The data was analyzed by identifying, examining and interpreting subsets from technical and non-technical perspectives [37]. This was done through the hermeneutics approach, which helps to gain meaning and understanding of the text about the phenomenon being studied [38].

\section{Result and discussion}

From the analysis of the NHI current state towards implementation, three factors: too much attention on political issues; imbalance between enabler and the enabled; and ETA insolation were found to be most prevalence. The factors as discuss below can potentially derail the implementation of the NHI, hence the deployment of ETA is crucially significant.

\subsection{Too much attention on political issues}

It is critical to understand the factors that influence the deployment of the ETA is an environment. Many architecture projects are not successful because of the different challenges that they encounter in the process [39]. Some of the challenges are attributable to the gap that exists between the architects and other stakeholders, which manifest from attention being given to nontechnical issues [40].

The implementation of the NHI has been overly politicized by the stakeholders, the political parties and some sections of the country. The policy and strategic documents that were gazetted between 2013 and to-date focus more on issues that manifest from political discourse. This includes how the NHI program will be funded; source of funding; and why should everyone be grouped or compelled to enroll in the program (DoH, 2017, 2015, 2013). As a result, there has been less attention on the enabling and supporting strategies towards successful implementation and practice of the NHI. Barrilleaux and Rainey explain how partisan politics outweigh universal healthcare program (Obamacare) at the expense of citizens [2]. This is a fundamental challenge which the South African government should take cognizance of, in the implementation of NHI.

\subsection{Imbalance between enabler and the enabled}

The discussion about the NHI has come a long way, about ten years. It got intensified in the last two years, more in 2019 as the program got approval by the Parliament (legislative authority) and gazetted by cabinet. The approval paved way for actual implementation and realization of the goal and objectives of the program. This require a balance between the enabled (NHI program) and enabler (IS/IT solutions). However, over the years discourse including strategic and policy documents has been more of one sided, in favor of the enabled rather than the enabler. Taken the USA account and experience into consideration [2], this can be detrimental for the implementation of NHI.

The imbalance affects capability of the enabler, which require vast and detailed planning and assessment IS/IT solutions and infrastructures. These include health systems, hardware platforms, software, databases, and network protocols. To ensure workability and successful enabling and support of the NHI, standard, policy, and principle must be adhered, through which appropriate IS/IT 


\section{F. Chitsa et al. / Advances in Science, Technology and Engineering Systems Journal Vol. 5, No. 2, 724-729 (2020)}

solutions and infrastructures are selected, for compatibility, integration, scalability and flexibility purposes. This is a report that the on-going pilot is experiencing challenges in some clinics, owing to lack of internet access caused by hardware and software failure as well as IT staff know-how [9]. The enterprise architecture (EA) which provides governance, standards, policies, and principles has hardly receive attention in the strategic documents [23]. A study highlights and explain how architecture can be used to manage complexities of systems [41].

\subsection{Enterprise technical architecture in isolation}

The government realizes the importance of health enterprise architecture [42]. What is missing is categorization of the domains, which is critical in the development of the EA. The pilot is already on-going without architecture, yet there are no signs of ETA development. The IS/IT solutions has dependency on each other, which makes their architectures, from platforms to integration critical. The ETA facilitates the integration, collaboration, standardization, deduplication, and reengineering of IS/IT solutions. Silo deployment of a domain or domains leads to lack of leverage and alignment between the enabled and the enabler [43]. As a result, many organizations are either unable to implement their ETA plans or only able to partially implement them [40].

The EA consists of domains which include business, information, application, and technical [44]. Although each of the domains has distinct objectives and deliverables, they are interconnected [45]. To avoid defragmentation, no domain is developed or deployed in isolation. Also, the domains are deployed in a chronological order, starting from the business to the technical architecture [46, 47]. This is to ensure holistic coverage, from business (health) goals and objectives, information exchanges and flows, to processing (eHealth) of activities and events [48]. This enacts integration and interoperability of systems towards successful implementation of the NHI systems

\section{Enterprise technical architecture}

In a more generic terms, an architecture is the art of designing a structure in order to manage the size and complexity [49]. An Architecture brings about pre and well planned procedures that are useful when implementing systems' complexities, which include integration, relationships of components [50] This study focuses on the enterprise technical architecture (ETA) domain of the enterprise architecture (EA) [47]. The technical architecture can be defined a set of standard guidelines that can be used to compel the choices of technology investment [51]. The architecture can be applied to guide any system because of its premise to provide a more solid foundation, enhanced support, and improved management approach [52] .

The ETA has been employed to guide, support, manage, and govern IS/IT solutions in many walks of life, including the health sector [13]. From health system's viewpoint, an architecture is important in a system's life in that it is used to guide data collection and management of applications [53]. The need for systems in healthcare to support interoperability as well as data sharing makes it difficult to implement or develop systems without an architecture [50]. In the context of healthcare, Hayes argues that money can be saved if an architecture could be used to guide processes including the selection and deployment of IS/IT solutions [54].
The increasing interest in the ETA is primarily to ensure, and to prevent prohibitive circumstances, such as loss of datasets due to lack of security, lack of connectivity, increased procurement and maintenance costs of IS/IT solutions, unreliability, noncompatibility as well as uncertainty of software and hardware [25]. This enacts the ETA as a process and not a project that has a clear start and finish [55]. As shown in Figure 1, the ETA is defined as a four phase approach, which are objective, development, implementation, and strategic [12]. The deployment of the ETA can on iteration basis address the integration and interoperability problems in health care systems [31].

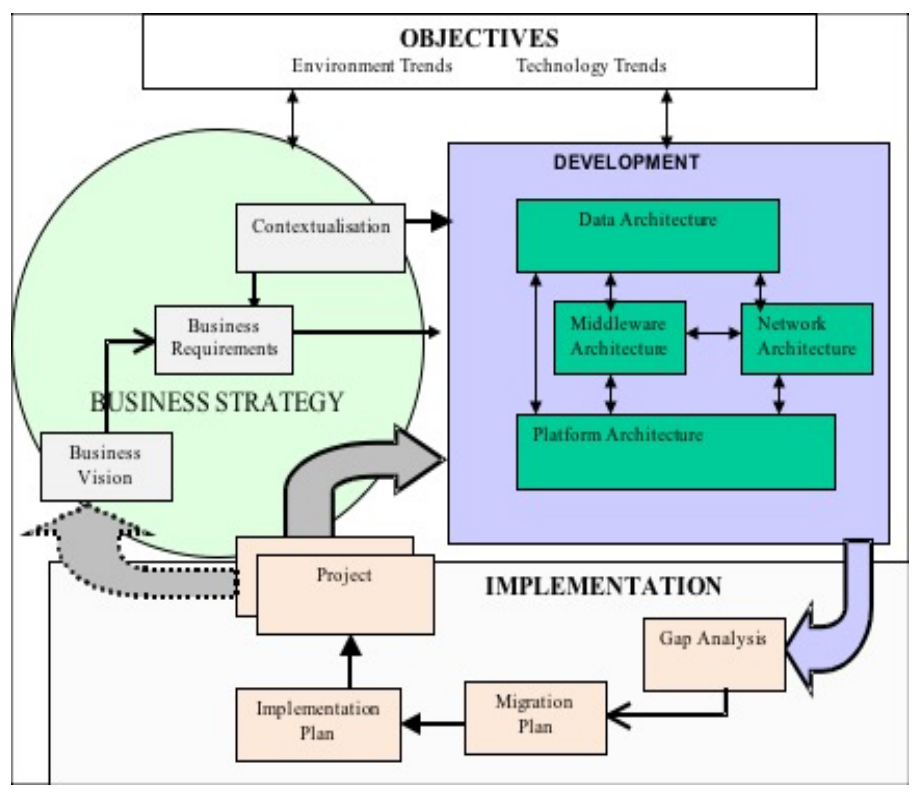

Figure 1: Technical Architecture Deployment [12]

Figure 1 is discussed, with focus on the cruciality of the ETA in the implementation of the NHI. It can be used to the four logical phases: Objectives, Business Strategy, Development, and Implementation are core in the deployment of technical architecture.

Phase 1: The ETA provides a baseline of the current and future states of an environment, which require managing change and gaining an accurate view of influencing factors [12]. No environment is stagnant, change is constant, which require the iterative approach of the ETA enabling the activities to the changing and transformative circumstances [56]. According to Gong and Janssen, the objectives shift and are refocused to align with societal or environmental needs [55]. The ETA facilitates assessment of the impact of technology change on the environment.

Phase 2: Phase 1 is the determinant factor for this phase [12]. This shows the ultimate dynamic and constantly changing nature of environment, which means that innovation is inevitable, and principles might become outdated. In this phase, technology challenges are addressed [55]. This allows the ETA to enable digitalization of health processes and activities toward quicker response in the delivering of services [56].

Phase 3: The development of the ETA is in four stages: requirements; classification of domains; documentation; and governance principles [12]. There are challenges in each of the 


\section{F. Chitsa et al. / Advances in Science, Technology and Engineering Systems Journal Vol. 5, No. 2, 724-729 (2020)}

stages. To mitigate against the challenges, Banaeianjahromi, N., \& Smolander suggest that it is crucial to understand the influencing factors during development [39]. In the context, there is a need to examine the relationship between architects and other stakeholders [40]. The development helps clarify the deployment and use of IS/IT solutions, which include processes, technical platforms, such as servers and databases, and of their mutual dependencies [57]. The development of the ETA provide insights into processes, available IS/IT solutions, and integrations methods [43].

Phase 4: As shown in Figure 1, the implementation phase consists of four stages: Gap analysis; Migration planning; Implementation planning; and Project [12]. Although architects are responsible for the implementation of the architectures, they depend on executives, on decision relating to non-technical issues, which often pose challenges to architecture solutions [40]. This can be attributed to lack of implementation strategy. Each component of the implementation should have assessment model. Otherwise, the development will continue to remain taxonomies [39].

\section{Conclusion}

In conclusion, the ETA should guide the implementation of the NHI. This should allow continuous examining and detecting of the factors that influence the implementation and practice of the program. These factors include technology infrastructures, information exchanges, and healthcare changing requirements (such as process, governance, and legislature).

The study discusses ETA towards its development for the implementation of the NHI in South Africa. The successful implementation of the NHI through the deployment of an ETA would be of interest and benefit to the stakeholders such as the policy-makers (government), health practitioners (doctors, nurses, and pharmacists) and the IT specialists, the enablers of the systems. Most importantly, development of an architecture will increase the society's confidence in the NHI program in that the ETA provides guidelines, which allow continuous examining and detecting of the factors that influence the implementation and practice of the program. The contributions of the study come from theoretical viewpoint. The theoretical contribution is the study's addition to existing literature from the perspectives of health informatics and ICT for development.

This study is limited, therefore it recommends that further studies should examine the factors that can influence the implementation of the NHI in South Africa, to understand the technology infrastructures, information exchange, and business (healthcare) requirements for the implementation of the NHI in South Africa. Through such studies an enterprise technical architecture can be developed, to guide the implementation of the NHI in the country.

\section{Conflict of Interest}

The authors declare no conflict of interest.

\section{Acknowledgment}

The authors would like to acknowledge and thank the Department of IT, CPUT for its support in carrying out this study. Input from the research forum at the IT department is also appreciated.

\section{References}

[1] M.R. Reich, J. Harris, N. Ikegami, A. Maeda, C. Cashin, E.C. Araujo, K. Takemi, T.G. Evans, "Moving towards universal health coverage: Lessons from 11 country studies" The Lancet, 387(10020), 811-816, 2016. https://doi.org/10.1016/S0140-6736(15)60002-2

[2] C. Barrilleaux, C. Rainey, "The Politics of Need. State Politics \& Policy" Quarterly, 14(4), 437-460, 2014. https://doi.org/10.1177/1532440014561644

[3] J.Y. Lai, J. Wang, "Switching attitudes of Taiwanese middle-aged and elderly patients toward cloud healthcare services: An exploratory study" Technological Forecasting and Social Change, 92, 155-167, 2015. https://doi.org/10.1016/j.techfore.2014.06.004

[4] N. Siegfried, T. Wilkinson, K. Hofman, K. Hofman, "Where from and where to for health technology assessment in South Africa? A legal and policy landscape analysis" South African Health Review, 41-48, 2017.

[5] R. Marten, D. McIntyre, C. Travassos, S. Shishkin, W. Longde, S. Reddy, J. Vega, "An assessment of progress towards universal health coverage in Brazil, Russia, India, China, and South Africa (BRICS)" The Lancet, 384(9960), 2164-2171, 2014. https://doi.org/10.1016/S0140-6736(14)600751

[6] T. Cheng, "Reflections On The 20th Anniversary Of Taiwan's Single-Payer National Health Insurance System” Health Affairs, 34(3), 502-510, 2015. https://doi.org/10.1377/hlthaff.2014.1332

[7] W. Cape, "Pursuing Universal Healthcare Coverage through the implementation of NHI", 2015.

[8] D. Martin, A.P. Miller, A.Quesnel-Vallée, N.R. Caron, B. Vissandjée, G.P. Marchildon, "Canada's universal health-care system: achieving its potential" The Lancet, 391(10131), 1718-1735, 2018. https://doi.org/10.1016/S01406736(18)30181-8

[9] K. Child, "National Health Insurance: pilot projects reveal deep problems", 2019.

[10] M. Jeffries, D. Phipps, R. L. Howard, A. Avery, S. Rodgers, D. Ashcroft, "Understanding the implementation and adoption of an information technology intervention to support medicine optimization in primary care: qualitative study using strong structuration theory" BMJ open, 7(5), e014810, 2017. http://dx.doi.org/10.1136/bmjopen-2016-014810

[11] C. Johnston, L. Gillam, "Legal and Ethical Issues Arising from the Use of Emerging Technologies in Paediatric Healthcare" QUT Law Review, 18(2), 93-110, 2019.

[12] T. Iyamu, "A Framework for Developing and Implementing the Enterprise Technical Architecture. Journal of Computer Science and Information Systems, 9(1), 189-206, 2012. https://doi.org/10.2298/CSIS101103040I

[13] A. Zimmermann, R. Schmidt, K. Sandkuhl, M. Wißotzki, D. Jugel, M. Möhring, "Digital enterprise architecture-transformation for the internet of things" in 2015 IEEE 19th International Enterprise Distributed Object Computing Conference Workshops and Demonstrations, EDOCW: 130-138. DOI: 10.1109/EDOCW.2015.16

[14] S. Devaraj, T.T. Ow, R. Kohli, "Examining the impact of information technology and patient flow on healthcare performance: A Theory of Swift and Even Flow ( TSEF ) perspective" Journal of Operations Management, 31(4), 181-192, 2013. https://doi.org/10.1016/j.jom.2013.03.001

[15] W. Raghupathi, V. Raghupathi, "Big data analytics in healthcare: promise and potential, 2(1), 1-10, 2014. DOIhttps://doi.org/10.1186/2047-2501-2-3

[16] B.A.L. Kellermann, S.S. Jones, "What It Will Take To Achieve The As-YetUnfulfilled Promises" Journal of Health Information Technology, 32(1), 6368, 2005. https://doi.org/10.1377/hlthaff.2012.0693

[17] E.A. Boogerd, T. Arts, L.J. Engelen, T.H. Belt Van De, "What Is eHealth ": Time for An Update? JMIR Research Protocols, 4(1) 2-5, 2015. DOI: $10.2196 /$ resprot.4065

[18] N. Phichitchaisopa, T. Naenna, "Original article: Factors Affecting the Adoption of Healthcare", 413-436, 2013.

[19] L. Mhlaba, A. Parry, D. Blaauw, "Is National Health Insurance a viable option for South Africa? Experiences from other countries. AfricaGrowth Agenda, 2016(10), 8-12, 2016.

[20] N. Leon, H. Schneider, E. Daviaud, “Applying a framework for assessing the health system challenges to scaling up mHealth in South Africa" BMC Medical Informatics and Decision Making, 12(1), 1-12, 2012. DOIhttps://doi.org/10.1186/1472-6947-12-123

[21] R. Passchier, "Exploring the barriers to implementing National Health Insurance in South Africa: The people's perspective" South African Medical Journal, 107(10), 836, 2017. DOI: 10.7196/SAMJ.2017.v107i10.12726

[22] J. Ross, F. Stevenson, R. Lau, E. Murray, "Factors that influence the implementation of e-health: a systematic review of systematic reviews" Implementation $\quad$ Science, 11(1), 1-12, 2016. DOIhttps://doi.org/10.1186/s13012-016-0510-7

[23] Department of Health "policy documents for 2013 and 2015" 2017.

[24] L. Liaropoulos, I. Goranitis, "Health care financing and the sustainability of health systems" International Journal for Equity in Health, 14(1), 5-8, 2015. DOI: https://doi.org/10.1186/s12939-015-0208-5 


\section{F. Chitsa et al. / Advances in Science, Technology and Engineering Systems Journal Vol. 5, No. 2, 724-729 (2020)}

[25] M. Aubakirov, E. Nikulchev, "Development of System Architecture for EGovernment Cloud Platforms" International Journal of Advanced Computer Science and Applications, 7(2), 253-258, 2016. DOI: 10.14569/IJACSA.2016.070235

[26] Q. Jiang, M.K. Khan, X. Lu, J. Ma, D. He, “A privacy preserving three-factor authentication protocol for e-Health clouds" The Journal of Supercomputing, 72(10), 3826-3849, 2016. DOIhttps://doi.org/10.1007/s11227-015-1610-x

[27] I. Odeyemi, J. Nixon, "Assessing equity in health care through the national health insurance schemes of Nigeria and Ghana: a review-based comparative analysis" International Journal for Equity in Health, 12(1), 1-18, 2013. DOIhttps://doi.org/10.1186/1475-9276-12-9

[28] L. Santos, A. Oliveira, J. Trindade, I. Barreto, P. Palmeira, Y. Comes, F. Santos, W. Santos, J. Oliveira, V. Pessoa, H. Shimizu, "Implementation research: towards universal health coverage with more doctors in Brazil" Bulletin of the World Health Organization, 95(2), 103-112, 2017. doi: 10.2471/BLT.16.178236

[29] O. Hanseth, B. Bygstad, "Flexible generification: ICT standardization strategies and service innovation in health care" European Journal of Information Systems, 24(6), 645-663, 2015. https://doi.org/10.1057/ejis.2015.1

[30] D.H. Olsen, "Enterprise Architecture management challenges in the Norwegian health sector" Procedia Computer Science, 121, 637-645, 2017. https://doi.org/10.1016/j.procs.2017.11.084

[31] M. Sajid, K. Ahsan, "Role of Enterprise Architecture in Healthcare Organizations and Knowledge-Based Medical Diagnosis System” Journal of Information Systems and Technology Management, 13(2), 181-192, 2016. https://doi.org/10.4301/S1807-17752016000200002

[32] B. Yazan, "The Qualitative Report Three Approaches to Case Study Methods in Education: Yin, Merriam, and Stake" The Qualitative Report, 20(2), 134 $152,2015$.

[33] H. Ridder, "The theory contribution of case study research designs "Business Research, 10(2), 281-305, 2017. DOIhttps://doi.org/10.1007/s40685-0170045-z

[34] V. Sherif, "Evaluating preexisting qualitative research data for secondary analysis" Forum Qualitative Sozialforschung/Forum:Qualitative Social Research, 19(2), 2018.

[35] M.P. Johnston, "Secondary Data Analysis: A method of which the time has come" Qualitatve and Quantative Methods in Libraryes (QQML), 3, 619-626, 2014. DOI: http://dx.doi.org/10.17169/fqs-19.2.2821

[36] G. Guest, E. Namey, K. McKenna, "How Many Focus Groups Are Enough? Building an Evidence Base for Nonprobability Sample Sizes" Field Methods, 29(1), 3-22, 2016. https://doi.org/10.1177/1525822X16639015

[37] A. Maxwell, T. Warner, F. Fang, "Implementation of machine-learning classification in remote sensing: an applied review" International Journal of $\begin{array}{llll}\text { Remote } & \text { Sensing, } & 39(9), & 2784-2817,\end{array}$ doi.org/10.1080/01431161.2018.1433343

[38] A.S. Lee, "Electronic Mail as a Medium for Rich Communication: An Empirical using Hermeneutic Interpretation, 18(2), 143-157, 1994.

[39] N. Banaeianjahromi, K. Smolander, "Lack of communication and collaboration in enterprise architecture development" Information Systems Frontiers, 21(4), 877-908, 2019. DOIhttps://doi.org/10.1007/s10796-0179779-6

[40] M. Dale, H. Scheepers, "Enterprise architecture implementation as interpersonal connection: Building support and commitment" Information Systems Journal, 30(1), 150-184, 2020.

[41] O.A. Adenuga, R.M. Kekwaletswe, A Coleman, "eHealth integration and interoperability issues: towards a solution through enterprise architecture" Health Information Science and Systems, 3(1), 1-8, 2015. DOIhttps://doi.org/10.1186/s13755-015-0009-7

[42] A. Gray, Y. Vawda, "Health policy and legislation" South African health review, 2016(1), 3-15, 2016

[43] R. Foorthuis, M. Van Steenbergen, S. Brinkkemper, W.A. Bruls, "A theory building study of enterprise architecture practices and benefits" Information Systems Frontiers, 18(3), 541-564, 2016. DOIhttps://doi.org/10.1007/s10796-014-9542-1

[44] D.D. Dang, S. Pekkola, "Systematic Literature Review on Enterprise Architecture in the Public Sector" Electronic Journal of e-Government, 15(2), 130-154, 2017.

[45] T. Iyamu, Enterprise Architecture: from concept to Practise (2nd Ed.). Australia: Heidelberg Press, 2015.

[46] K. Sandkuhl, U. Seigerroth, J. Kaidalova, "Towards Integration Methods of Product-IT into Enterprise Architectures" In 2017 IEEE 21st International conference on Enterprise Distributed Object Computing Workshop (EDOCW),: Quebec City, Canada, 2017: DOI: 10.1109/EDOCW.2017.13

[47] I. Shaanika, T. Iyamu, "Deployment of enterprise architecture in the Namibian Government: The use of activity theory to examine the influencing factors" Electronic Journal of Information Systems in Developing Countries, 71(1), 1-21, 2015. https://doi.org/10.1002/j.1681-4835.2015.tb00515.x
[48] J. Whelan, G. Meaden, Business Architecture: A Practical Guide, Gower publishing, Ltd., 2016.

[49] C. Fischer, R. Winter, S. Aier, "What is an enterprise architecture principle? Towards a consolidated definition" Studies in Computational Intelligence, 317(Ieee 2000), 193-205, 2010.

[50] K. Hjort-Madsen, "Enterprise architecture implementation and management: A case study on interoperability" in 2006 Hawaii International Conference on System Sciences, Kauia, HI, USA 2006 DOI: 10.1109/HICSS.2006.154

[51] R. Giachetti, "Design of enterprise systems: Theory, architecture, and methods. CRC Press, Taylor \& Francis Group, 2016.

[52] Z. Chen, X. Zhang, K. He, "Research on the Technical Architecture for Building CPS and Its Application on a Mobile Phone Factory" in 2017 Enterprise Systems 5th International Conference on Enterprise Systems: Industrial Digitalization by, ES 2017: 76-84. DOI: 10.1109/ES.2017.20

[53] Y. Zhang, M. Qiu, C.W. Tsai, M.M. Hassan, A. Alamri, "Health-CPS: Healthcare cyber-physical system assisted by cloud and big data" IEEE Systems Journal, 11(1), 88-95, 2017. DOI: 10.1109/JSYST.2015.2460747

[54] G. Hayes, "The NHS Information Technology (IT) and social care review 2009: A synopsis" Informatics in Primary Care, 18(2), 81-88, 2010. DOI: http://dx.doi.org/10.14236/jhi.v18i2.757

[55] Y. Gong, M. Janssen, "The value of and myths about enterprise architecture" International Journal of Information Management, 46, 1-9, 2019. https://doi.org/10.1016/j.ijinfomgt.2018.11.006

[56] J. Wichmann, M. Wißotzki, "An Exploration of Enterprise Architecture Research in Hospitals" In 2019 International Conference on Business Information Systems, Seville, Spain. https://doi.org/10.1007/978-3-03036691-9_8

[57] E. Niemi, S. Pekkola, "The Benefits of Enterprise Architecture in Organizational Transformation" Business \& Information Systems Engineering, 1-13, 2019. DOIhttps://doi.org/10.1007/s12599-019-00605-3 